\title{
EDITORIAL
}

\section{The end of the wormwars?}

\author{
David Tovey, Julia H Littell, Jeremy M Grimshaw \\ Cochrane Database of Systematic Reviews 2016;(9):ED000116 https://doi.org/10.1002/14651858.ED000116
}

Publication date: 27 September 2016

When science clashes with the application of good intentions combined with strong beliefs (plus, in many cases considerable academic and professional interest), the fallout can be bruising. This has been experienced at first hand by Cochrane researchers questioning the use of neuraminidase inhibitors for preventing or treating influenza, the effect of screening mammography for breast cancer, and the benefit of deworming populations in endemic areas.[1][2][3] In this third case the dispute that has followed the relevant Cochrane Review throughout its long history has attracted its own Twitter hashtag (twitter.com/hashtag/ wormwars) and has been notable for the ferocity and personal nature of many of the attacks.[4]

Periodic deworming for children living in endemic areas has been advocated by organizations as influential as the World Health Organization, the World Bank, and the Bill \& Melinda Gates Foundation, and it has been considered to be a fundamental solution to the problems associated with endemic soil-transmitted helminth infections, looking beyond eradication of infection to important outcomes such as school attendance and cognitive development.[3]

The Cochrane Review of mass deworming programmes was first published in 1998 and has been regularly updated. In 2001 the authors concluded that there was "limited evidence that routine treatment of children in areas where helminths are common has small effects on weight gain, but this is not consistent between trials." [5] The 2012 update brought in a logic framework, assessment of the certainty of the evidence using GRADE, and a study from Kenya previously excluded because of concerns about co-intervention that were resolved by dialogue with the Kenyan trial authors. [6] The most recent edition was published in 2015 and includes 44 trials with a total of 67,672 participants (plus an additional mortality trial in over 1 million children).[3] It shows consistent evidence of no important effect for key outcomes, including weight, height, haemoglobin, cognition, exam performance, and mortality, with limited data on school attendance, where findings are mixed and at risk of bias.

As the evidence of no effect presented in the Cochrane Review has become firmer, the opposing views have become more vociferous, with some concerted efforts to undermine the findings and even harm the professional reputation of the researchers involved.

In this context the publication of a systematic review and network meta-analysis of deworming strategies by researchers working within the Campbell Collaboration provides us with an opportunity to compare the findings from two independently conducted, high-quality reviews.[7] Furthermore, the Campbell researchers, led by Vivien Welch, have attempted to address the more substantial criticisms made of the Cochrane Review, including the inclusion of three large observational longer term studies that did not meet the eligibility criteria of the Cochrane Review. However, deworming advocates seeking endorsement of their criticisms of the Cochrane researchers will be disappointed. Indeed, it is hard to imagine how the Campbell review could have more powerfully exonerated the Cochrane counterpart. The results and conclusions could have come from the same review: little or no evidence of important benefit for key outcomes such as weight gain $(0.09 \mathrm{~kg} ; 95 \% \mathrm{Cl} 0.04 \mathrm{~kg}$ less to $0.2 \mathrm{~kg}$ more), stunting (8/1000 fewer; $95 \% \mathrm{Cl} 48 / 1000$ fewer to $32 / 1000$ more), cognition (short-term attention -0.23 points on 100 -point scale; $95 \% \mathrm{Cl}-0.6$ to 0.14 ), school attendance (1\% higher; $95 \% \mathrm{Cl} 1 \%$ lower to $3 \%$ higher), or mortality ( $1 / 1000$ fewer; $95 \%$ Cl 3/1000 fewer to $1 / 1000$ more).[7]

Importantly, the review does not support claims that untreated children benefit from being exposed to treated children in their community. This proposition, based on earlier research was challenged recently by a 3ie-funded replication study of the same Kenyan trial added to the Cochrane Review in 2012, although the issue remains controversial.[8][9][10] If such an effect existed, it might be expected that cluster trials would be better able to demonstrate beneficial outcomes from deworming, compared with studies where individuals were randomized. However, the Campbell researchers found no evidence of a difference in a sensitivity analysis of cluster trials, and their sub-group analysis comparing these to individually randomized studies also showed no statistically significant effect.

The Campbell researchers also addressed the effects of deworming programmes aimed at counteracting schistosomiasis, which was not addressed in the Cochrane Review. Here they concluded that deworming "resulted in larger gains in weight and no difference in effect on height, cognition or school attendance".[7]

What happens next will be illuminating. The cost of deworming per individual treated is often said by the advocates to be trivial, but because of the prevalence of the problem, worldwide costs are substantial, and the estimates usually exclude the cost of services in delivering the intervention. The historic arguments in favour of the interventions as being cost effective are moot if there are no important health, educational, or cognitive benefits in properly designed studies. There are opportunity costs to health systems when they divert resources to supporting 
implementation of interventions that confer little meaningful benefit, however cheap they are.

It will be challenging for individuals and organizations to admit that current investment is probably not worthwhile. But in the end, good intentions and strong beliefs should not displace evidence as a basis for rolling out mass interventions. Replication plays an important role in science and the determination of truth, and for good reason. Cochrane and Campbell researchers invest heavily in quality assurance processes to reduce the need for duplication of effort and research waste, but given the contentious nature of this area, this replication is probably justified. The results of these two independently conducted reviews are now clear and consistent. Ceasing to deliver a large complex programme into which hope, commitment, and resources have been invested is a substantially more burdensome intervention than deciding not to implement an activity in the first place. The Campbell authors recommend more research aimed at identifying those groups, if any, who might benefit from deworming. There is no dispute that treating children infected with worms is worthwhile, but the findings of the two systematic reviews together provide a strong case against the current population-wide programmes.

\section{Author Information}

David Tovey1 , Julia H Littell2,3, Jeremy M Grimshaw2,4,5

${ }^{1}$ Cochrane, London, UK. ${ }^{2}$ Campbell Collaboration. ${ }^{3}$ Graduate School of Social Work and Social Research, Bryn Mawr College, Bryn Mawr, USA. ${ }^{4}$ Ottawa Hospital Research Institute. ${ }^{5}$ University of Ottawa, Canada

\section{Declarations of interest}

The authors have completed the ICMJE form for disclosure of potential conflicts of interest (forms available upon request). DT is Editor in Chief and Deputy CEO of Cochrane. JHL is Editor in Chief of the Campbell Collaboration. JMG is President of the Board of the Campbell Collaboration.

\section{Provenance and peer review}

This editorial was commissioned and was not externally peer reviewed.

\section{References}

1. Jefferson T, Jones MA, Doshi P, Del Mar CB, Hama R, Thompson MJ, et al. Neuraminidase inhibitors for preventing and treating influenza in adults and children. Cochrane
Database of Systematic Reviews 2014;(4):CD008965. doi.org/10.1002/14651858.CD008965.pub4

2. Gøtzsche PC, Jørgensen KJ. Screening for breast cancer with mammography. Cochrane Database of Systematic Reviews 2013; (6):CD001877. doi.org/10.1002/14651858.CD001877.pub5

3. Taylor-Robinson DC, Maayan N, Soares-Weiser K, Donegan S, Garner P. Deworming drugs for soil-transmitted intestinal worms in children: effects on nutritional indicators, haemoglobin, and school performance. Cochrane Database of Systematic Reviews 2015;(7):CD000371. doi.org/10.1002/14651858.CD000371.pub6

\section{Hawkes N. Deworming debunked. BMJ 2013;346:e8558 doi.org/10.1136/bmj.e8558}

5. Dickson R, Awasthi S, Demellweek C, Williamson P. Anthelmintic drugs for treating worms in children: effects on growth and cognitive performance. Cochrane Database of Systematic Reviews 2000;(2):CD000371. doi.org/10.1002/14651858.CD000371

6. Taylor-Robinson DC, Maayan N, Soares-Weiser K, Donegan S, Garner P. Deworming drugs for soil-transmitted intestinal worms in children: effects on nutritional indicators, haemoglobin and school performance. Cochrane Database of Systematic Reviews 2012;(11):CD000371. doi.org/10.1002/14651858.CD000371.pub5

7. Welch VA, Ghogomu E, Hossain A, Awasthi S, Bhutta Z, C Cumberbatch, et al. Deworming and adjuvant interventions for improving the developmental health and well-being of children in low- and middle-income countries: a systematic review and network meta-analysis. Campbell Systematic Reviews 2016;7. doi.org/10.4073/csr.2016.7

8. Miguel E, Kremer M. Worms: identifying impacts on education and health in the presence of treatment externalities. Econometrica 2004;72(1):60. doi.org/10.1111/ j.1468-0262.2004.00481.x

9. Aiken AM, Davey C, Hargreaves JR, Hayes RJ. Re-analysis of health and educational impacts of a school-based deworming programme in western Kenya: a pure replication. International Journal of Epidemiology 2015;44(5):1572-80. doi.org/10.1093/ije/ dyv127

10. Hicks JH, Kremer M, Miguel E. Estimating deworming school participation impacts and externalities in Kenya: a comment on Aiken et al. (2014). Original author response to 3ie Replication Paper 3, part 1. Washington, DC: International Initiative for Impact Evaluation (3ie), 2014. www.3ieimpact.org/media/ filer_public/2014/10/20/worms-3ie-pure-response_2014-10-10final_3ie2.pdf (accessed 15 September 2016). 